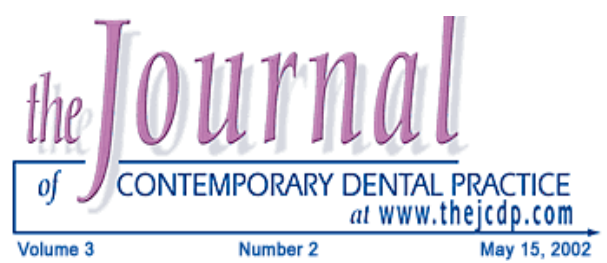

\title{
The Clinical Effectiveness of a Novel Power Toothbrush and Its Impact on Oral Health
}

\author{
Aaron R. Biesbrock, DMD, PhD, MS; Linda M. Bayuk, MBA; \\ Marie-Vee Santana, PhD; Darin S. Yates, MBA; Robert D. Bartizek, MS
}



Abstract

This review details the invention and clinical testing of a new power toothbrush designed to provide a low cost, effective toothbrush, which has a combination of a round oscillating head in conjunction with fixed bristles. The data demonstrate this power toothbrush (Crest SpinBrush $^{\mathrm{TM}}$ ) is an effective cleaning toothbrush with respect to plaque removal. Four independent 4-period crossover studies, where subjects used each brush twice, have demonstrated that brushing with this power toothbrush results in $10-40 \%$ greater plaque removal relative to a series of control manual toothbrushes. Separate research has confirmed that adults and children tend to brush longer, $35.8 \%$ and $38.3 \%$ respectively, when using this power toothbrush relative to manual toothbrushes.

In addition, it has been shown to be superior to a battery-powered toothbrush (Colgate ActiBrush ${ }^{\mathrm{TM}}$ ) in two independent studies and has demonstrated comparable efficacy to a leading powered toothbrush (Oral-B Ultra Plaque Remover ${ }^{\circledR}$ ). In parallel, this power toothbrush has also been shown to be safe relative to manual and power toothbrushes.

Keywords: SpinBrush, power toothbrush, plaque removal

Citation: Biesbrock AR, Bayuk LM, Santana MV, et. al. The Clinical Effectiveness of a Novel Power Toothbrush and Its Impact on Oral Health. J Contemp Dent Pract 2002 May;(3)2: 001-010.

\section{(c) Seer Publishing}




\section{Introduction}

Power toothbrushes were introduced to consumers in the 1960's and have continued to evolve in both design and performance. More recently, powered toothbrushes with round oscillating bristle heads have become a prominent aid for delivering oral hygiene in both the United States and Europe. A number of clinical studies have demonstrated that these power toothbrushes deliver greater plaque removal compared to manual toothbrushes, leading to growing acceptance in the dental community that power toothbrushes offer superior plaque control efficacy compared to manual toothbrushes. ${ }^{1-15}$ Importantly, these benefits appear to be applicable to the general population, as in a large practice-based study examining 16,903 patients in which dental professionals reported that $80.5 \%$ of their patients had noticeable benefits with respect to plaque removal and gingival condition. ${ }^{16}$

However, by the late 1990's, examination of the evolving technology in the power toothbrush market demonstrated a growing tendency toward increasingly complex and expensive methods of achieving motorized motions in the bristles and heads of toothbrushes to aid in more effective cleaning of teeth. The commercial marketplace had evolved into two distinct markets. On the higher price end (\$20-\$100), was a steady stream of novel power toothbrushes that provided increasingly complex motions to the bristles and brush head at a premium price. At the same time, the more affordable end of the market had become the province of very simple power toothbrushes that only vibrated through the use of an offset weight attached to the motor shaft. These low cost power toothbrushes provided very little true additional cleaning benefit with their use, since no vigorous motion was transmitted to the cleaning surface of the brush.

Recently, a new low cost, effective battery powered toothbrush (Crest ${ }_{\circledast}$ SpinBrush $^{\mathrm{TM}}$ ) was introduced, which has a combination of a round oscillating head in conjunction with fixed bristles. The brush head, with its combination of fixed and moving bristles, was designed to have a more traditional sized brush head permitting patients to brush their teeth in an optimal

\begin{tabular}{|l|l|}
\hline 3000 B.C. & \multicolumn{1}{c|}{ Toothbrush Development Timeline } \\
\hline 1400 's & $\begin{array}{l}\text { Egyptians use small branches with frayed ends to clean teeth } \\
\text { a bamboo or bone handle }\end{array}$ \\
\hline 1600 's & $\begin{array}{l}\text { European travelers to China bring back toothbrush, replace wild boar hair } \\
\text { with softer horse hair }\end{array}$ \\
\hline 1885 & Companies began to mass produce manual toothbrushes \\
\hline 1938 & First nylon bristles introduced \\
\hline 1950 & Nylon bristles were made softer \\
\hline 1960 & $1^{\text {st }}$ electric toothbrush introduced in the U.S. \\
\hline 1987 & $1^{\text {st }}$ rotary action electric toothbrush for home use introduced \\
\hline 2000 & Low-price power toothbrushes grow power brush market \\
\hline
\end{tabular}




\section{Clinical Plaque Removal Protocol}

\begin{tabular}{|c||c|c|c|}
\hline \multicolumn{1}{|c|}{} & \multicolumn{2}{|c|}{ Morning Visit } \\
\cline { 2 - 4 } 12 hours pre-test & $\begin{array}{c}\text { Pre-brushing } \\
\text { plaque assessed }\end{array}$ & 1-minute brushing & $\begin{array}{c}\text { Post-brushing } \\
\text { plaque assessed }\end{array}$ \\
\hline $\begin{array}{c}\text { No eating, drinking, } \\
\text { smoking, gum or oral } \\
\text { hygiene prior to visit }\end{array}$ & $\begin{array}{c}\text { Plaque disclosed and } \\
\text { scored by examiner }\end{array}$ & $\begin{array}{c}\text { Normal brushing } \\
\text { regimen with standard } \\
\text { NaF dentifrice }\end{array}$ & $\begin{array}{c}\text { Plaque disclosed and } \\
\text { scored by examiner }\end{array}$ \\
\hline
\end{tabular}

manner recommended by a dentist, while the motorized circular portion of the brush promotes more effective cleaning. In addition, this brush has an angled shaft to permit easier access to the back teeth in the oral cavity. Importantly, it was developed specifically to provide a low cost alternative to existing power toothbrushes, while providing proven performance with respect to oral health.

\section{Clinical Efficacy Studies}

The current clinical support for Crest SpinBrush efficacy consists of seven plaque removal brushing efficiency studies. ${ }^{17-22}$ The clinical design used to demonstrate efficacy is well established in the literature and has been previously well characterized. ${ }^{1,717-22}$ Briefly, all seven of the studies were randomized, controlled, examiner-blind, crossover designs (six of seven studies were cross-over, with the last study being parallel) that examined plaque removal with a battery operated power toothbrush compared to a control toothbrush following a single use.

Study participation was on a voluntary basis following written informed consent of the subjects. A population of healthy adults with a minimum of 15 gradable teeth, between the ages of 18-70, was recruited. Prospective subjects were excluded from the study for the following reasons:

- Obvious periodontal disease

- Presence of orthodontic appliances or removable prosthesis

- Presence of 5 or more carious lesions requiring treatment

- Pregnancy

- Or inability to comply with the study protocol
Subjects refrained from all oral hygiene procedures and chewing gum for 12 hours prior to their appointment. In addition, the subjects did not eat, drink, or smoke the morning of their appointment. Subjects were disclosed with Red-Cote ${ }^{\circledast}$ disclosing solution and examined by a blinded examiner for baseline overnight plaque using the Turesky Modification of the Quigley-Hein Index. ${ }^{23,24}$

The plaque examination was scored on the buccal and lingual surfaces of all teeth with the exception of the third molars. The maximum number of teeth was 28 with 56 scoreable sites, while the minimum number of teeth was 15 with 30 scorable sites. Subjects were instructed to brush their teeth with their assigned toothbrush following their normal regimen for 1 minute in the presence of a monitor. A controlled pre-measured quantity of marketed $0.243 \%$ sodium fluoride dentifrice (Crest Cavity Protection) was dispensed to each subject by the supervisor to control dosing variability. Subjects were re-disclosed with Red-Cote disclosing solution and reexamined by the blinded examiner.

\begin{tabular}{|l} 
Modified Quigley-Hein Scoring Procedure \\
$0=$ No Plaque. \\
$1=$ Separate flecks of plaque at the cervical margin. \\
$2=\begin{array}{l}\text { A thin, continuous band of plaque (up to } 1 \mathrm{~mm} \text { ) at the } \\
\text { cervical margin. }\end{array}$ \\
$3=\begin{array}{l}\text { A band of plaque wider than } 1 \mathrm{~mm} \text {, but covering less } \\
\text { than } 1 / 3 \text { of the side of the crown of the tooth. }\end{array}$ \\
$4=\begin{array}{l}\text { Plaque covering a least } 1 / 3 \text {, but less than } 2 / 3 \text { of the } \\
\text { side of the crown of the tooth. }\end{array}$ \\
$5=\begin{array}{l}\text { Plaque covering } 2 / 3 \text { or more of the side of the crown } \\
\text { of the tooth. }\end{array}$
\end{tabular}


For statistical comparison, the plaque scores were averaged on a per subject basis. Each subject had a single whole-mouth average score for baseline and for the exam following a one-minute brushing with their assigned toothbrush. For the six cross-over studies, the difference (baseline minus post-brushing) in average scores was calculated and analyzed using an analysis of covariance for a crossover design, with baseline whole-mouth average score as the covariate and terms in the model for subjects, periods, treatments, and residual (carryover) effects. This analysis is referred to as the full model analysis. A reduced model without residual effects was used for the final analysis. In the one parallel study, the difference (baseline minus post-brushing) in average scores was calculated and analyzed for treatment group differences using an analysis of covariance with baseline whole-mouth average score as the covariate. A nonparametric Wilcoxon Rank-Sum Test was also performed on the baseline minus post-brushing differences as a confirmatory analysis. All statistical tests of hypotheses were two sided and employed a level of significance of $p=0.05$.

\section{Clinical Efficacy Studies}

The efficacy of this new power toothbrush can be divided into three areas relative to:

1. Manual toothbrushes

2. Battery operated power toothbrushes

3. More expensive power toothbrushes

Four independent 4-period crossover studies, where subjects used each brush twice, have demonstrated that brushing with this new power toothbrush (SpinBrush) results in greater plaque removal relative to control manual toothbrushs. ${ }^{18,19,20}$ (Table 1)

Two independent studies have compared this new power toothbrush to a positive control battery powered toothbrush (Colgate ActiBrush ). ${ }^{17,22}$

Table 1: Plaque Removal Effectiveness of Crest SpinBrush Relative to Manual Toothbrushes

\begin{tabular}{|l|c|c|c|c|c|}
\hline Manual Brush & $\mathrm{N}$ & $\begin{array}{c}\text { SpinBrush } \\
\text { Plaque Removal }\end{array}$ & $\begin{array}{c}\text { Manual Brush } \\
\text { Plaque Removal }\end{array}$ & $\begin{array}{c}\text { Percent Improvement vs. } \\
\text { Manual Brush }\end{array}$ & $p$ Value \\
\hline Colgate Navigator & 40 & $0.48+0.02$ & $0.35+0.02$ & $37 \%$ & $p<0.001$ \\
\hline Crest Extender & 42 & $0.49+0.02$ & $0.44+0.02$ & $10 \%$ & $p=0.040$ \\
\hline Colgate Wave & 37 & $0.70+0.05$ & $0.59+0.05$ & $20 \%$ & $p<0.001$ \\
\hline Colgate Plus & 35 & $0.87+0.02$ & $0.62+0.02$ & $40 \%$ & $p<0.001$ \\
\hline
\end{tabular}

In both these studies, the new power toothbrush was found to deliver greater plaque removal relative to the positive control battery powered toothbrush, which is widely recognized as an effective power toothbrush. (Table 2)

The efficacy of the positive control battery powered toothbrush has been well-characterized in the literature. In one recent study, it was shown to deliver similar plaque removal efficacy to a control electric powered toothbrush (Oral-B Plaque Remover $).^{25}$ The brushes were not statistically significantly different, although the positive control battery powered toothbrush did demonstrate directionally (17\%) more plaque removal than the Oral-B Plaque Remover. It has also been shown to remove plaque better than multiple manual toothbrushes in a series of post-brushing and short-term studies. ${ }^{7-11}$

In post-brushing studies, the power toothbrush $\left(\right.$ Colgate ActiBrush ${ }^{\oplus}$ ) removed plaque from 30$100 \%$ better compared to five different manual toothbrushes (including Oral-B CrossAction $\left.{ }^{\circledR}\right){ }^{7,8}$ In studies longer than a month in duration, greater plaque reductions $(9.4-36.8 \%)$ were observed with the power toothbrush relative to three different manual toothbrushes. ${ }^{8-11}$ In one of these studies, statistically significant reductions in plaque were observed relative to the standard American Dental Association reference manual toothbrush. ${ }^{11}$
Finally, the Crest SpinBrush has been compared to a positive control electric power toothbrush (the Oral-B Ultra Plaque Remover). ${ }^{21}$ In this study, the whole-mouth plaque reduction data showed that, on average, the new power toothbrush removed $3.6 \%$ more plaque than the positive control electric power toothbrush. This difference was not statistically significant $(p=0.645)$, and the upper limit of a one-sided $95 \%$ confidence interval on the positive control electric power toothbrush minus new power toothbrush difference was found to be $9.4 \%$ of the positive control electric power toothbrush mean. This finding supports that the new power toothbrush is at least as good as the positive control electric power toothbrush with respect to plaque removal, following a single brushing. The positive control electric power toothbrush has been shown to be a more effective toothbrush than the clinically proven Oral-B Plaque Remover.

In in vitro testing, the positive control electric power toothbrush removed statistically significantly more plaque as compared to the Oral-B Plaque Remover, with the toothbrushes removing $85.3 \%$ and $72.9 \%$ of artificial plaque, respectively. ${ }^{26}$ In addition, the positive control electric power toothbrush has been shown to remove statistically significantly more stain (area and intensity) with both one and two minutes of brushing and directionally greater plaque relative to the Oral-B Plaque Remover in a pair of clinical studies. ${ }^{27}$ Importantly, in a large based practice-based study examining

Table 2: Plaque Removal Effectiveness of Crest SpinBrush Relative to Battery Powered Toothbrushes

\begin{tabular}{|l|c|c|c|c|c|}
\hline Power Brush & $\mathrm{N}$ & $\begin{array}{c}\text { SpinBrush } \\
\text { Plaque Removal }\end{array}$ & $\begin{array}{c}\text { ActiBrush } \\
\text { Plaque Removal }\end{array}$ & $\begin{array}{c}\text { Percent Improvement vs. } \\
\text { ActiBrush }\end{array}$ & $p$ Value \\
\hline Colgate ActiBrush & 59 & $0.47+0.03$ & $0.33+0.03$ & $40 \%$ & $p=0.013$ \\
\hline Colgate ActiBrush & 39 & $0.66+0.02$ & $0.43+0.02$ & $55 \%$ & $p<0.001$ \\
\hline
\end{tabular}


Table 3: Plaque Removal Effectiveness of Crest SpinBrush Relative to a High-End Powered Toothbrush

\begin{tabular}{|l|c|c|c|c|c|}
\hline Power Brush & $\mathrm{N}$ & $\begin{array}{c}\text { SpinBrush } \\
\text { Plaque Removal }\end{array}$ & $\begin{array}{c}\text { Ultra } \\
\text { Plaque Removal }\end{array}$ & $\begin{array}{c}\text { Percent Improvement vs. } \\
\text { Ultra }\end{array}$ & $p$ Value \\
\hline $\begin{array}{l}\text { Oral-B Ultra } \\
\text { Plaque Remover }\end{array}$ & 38 & $0.46+0.04$ & $0.45+0.04$ & $4 \%$ & $p=0.645$ \\
\hline
\end{tabular}

16,903 subjects, dental professionals reported that $80.5 \%$ of their patients had noticeable benefits with respect to plaque removal and improved gingival condition. ${ }^{16}$ Study participants also noticed a first-person benefit with $74 \%$ reporting an improvement in oral health. Following eight months of use, two-thirds of the 282 dentists interviewed considered the power toothbrush the most effective method of toothbrushing. Furthermore, in another study the Oral-B Ultra Plaque Remover and Oral-B 3D removed $57.3 \%$ and $61.3 \%$ of plaque, respectively, following 2 minutes of brushing with the apparent difference in plaque removal efficacy of the electric toothbrushes being quite small, albeit statistically significant. ${ }^{28}$

No adverse events, including oral soft or hard tissue trauma, were attributed to Crest SpinBrush in any of these seven studies. ${ }^{17-22}$ This observation is consistent with the established safety profile of this power toothbrush. Previously in a 4-week safety study, it was found to be as safe as a marketed power toothbrush and safer than an ordinary flat bristle profile manual toothbrush. ${ }^{29}$

\section{Patient Compliance Studies}

Tooth brushing duration has been shown to have a profound impact on brushing effectiveness, with longer brushing being highly correlated to more effective plaque removal. ${ }^{5,30,31}$ Longer brushing durations have been reported to result in an almost linear reduction in plaque on tooth surfaces. ${ }^{31}$ The clinical study data demonstrating Crest SpinBrush superiority to manual toothbrushes and battery powered toothbrushes was generated in controlled clinical settings where brushing duration was one minute for all brushes examined to control for the impact of brushing duration. Voluntary responses from Crest SpinBrush users suggest that in their daily routine they tend to brush longer than they do with manual toothbrushes. In order to explore the generalizability of these voluntary consumer reports, brushing duration was examined in two randomized controlled studies to examine whether subjects brush longer with this power toothbrush relative to a control manual toothbrush.

The first study used a parallel-group design with two groups: (1) a power toothbrush group and (2) a control manual-toothbrush group. There were 64 adults recruited for this study, and they were randomly assigned to one of the two groups. The subjects in the power toothbrush group received the Crest SpinBrush classic, and the manual-toothbrush group received the Oral-B P40 Indicator. Subjects were asked to time their brushing in the morning and in the evening with a stopwatch and record their brushing times in the diary provided.

The study lasted two weeks. During these two weeks, the subjects brushed using the toothbrush provided. Subjects were asked to maintain their brushing routines as normal as possible within the restrictions of the study. This involved using the toothpaste that they normally use, brushing in the pattern that they normally brush, and maintaining all other behaviors related to their brushing habits with consistency. Results from the study indicate that adults' mean brushing times were significantly longer when using the power toothbrush than when compared to a manual brush.

The second study used the same parallel-group design with two groups: (1) a power toothbrush group and (2) a control manual-toothbrush group. There were 60 children recruited for this study, and they were randomly assigned to one of the two groups. The children in the power toothbrush

Table 4: Brushing Duration in Adults

\begin{tabular}{|l|c|c|c|c|}
\hline Tooth Brush & N & Brushing Duration (Sec) & Percent Increase & $p$ Value \\
\hline Crest SpinBrush & 30 & 120.90 & $35.8 \%$ & $p=0.003$ \\
\hline Oral-B P40 Indicator & 30 & 89.05 & ---- & \\
\hline
\end{tabular}


Table 5: Brushing Duration in Children

\begin{tabular}{|l|c|c|c|c|}
\hline Tooth Brush & N & Brushing Duration (Sec) & Percent Increase & $p$ Value \\
\hline Crest SpinBrush & 24 & 102.47 & $38.3 \%$ & $p=0.020$ \\
\hline Crest Youth Manual & 24 & 74.09 & ----- & \\
\hline
\end{tabular}

group received either a mermaid design (girls) or race-car design (boys) Crest SpinBrush, and the manual-toothbrush group received the $\mathrm{Crest}_{\circledast}$ Youth manual brush. Parents were asked to time their children while brushing in the morning and in the evening and record their brushing times in the diary provided.

This study also lasted two weeks. During these two weeks, the subjects brushed using the toothbrush provided. Similarly, the subjects were asked to maintain their brushing routines as normal as possible within the restrictions of the study. As in the first study, brushing habits were maintained consistent throughout the study. The results of this study indicated that children's mean brushing times were significantly longer when using the power toothbrush than when using a manual brush.

\section{Impact on Dental Care}

Prior to the launch of this novel power brush, which was first marketed as Dr. Johns' SpinBrush in late 1999, the majority of the power toothbrush models marketed in the United States consisted

Figure 1: Retail Sales in the United States

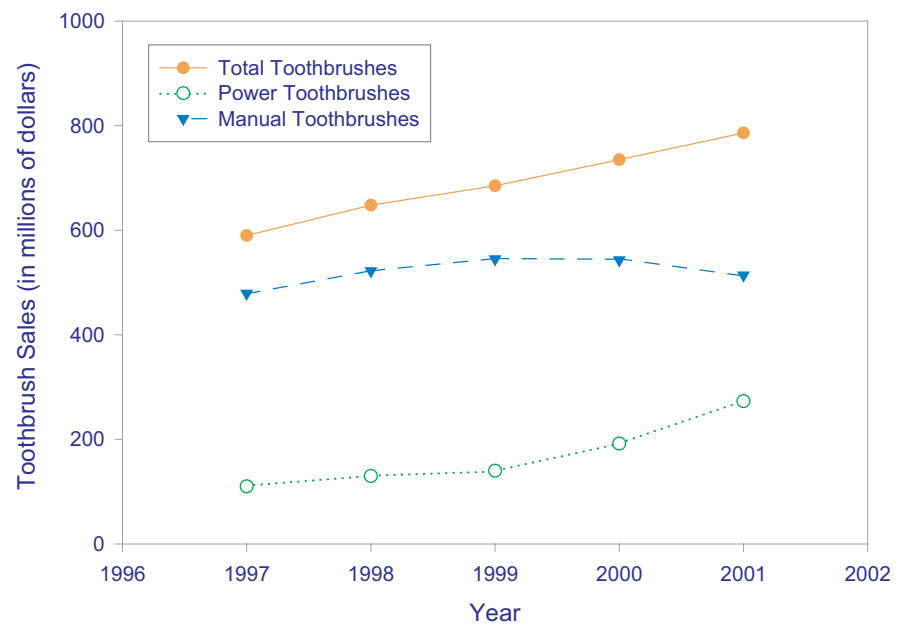

* Data represents combined food, drug, Kmart, \& Target stores, acquired from Information Resources, Incorporated (Chicago IL). of relatively expensive complex motorized toothbrushes. While many of these toothbrushes offered clinically proven health benefits through effective plaque removal, they were financially infeasible for a large percentage of the population. The new power toothbrush was novel in that it delivered as good or better cleaning efficacy than powered toothbrushes at a significantly lower cost. In parallel, the US power toothbrush market segment has demonstrated explosive growth since 1999. (Figure 1) Retail sales of power toothbrushes have almost doubled in the last two years. This growth in power toothbrushes is driving the overall toothbrush market sales, which is up $15 \%$ since 1999 on flat unit sales. Toothbrush users are clearly trading up from manual toothbrushes to powered toothbrushes following the removal of past pricing barriers. This growth appears to have been directly driven by the introduction of the Crest SpinBrush (formerly known as Dr. Johns' SpinBrush until April 2001). (Figure 2) Since the summer of 2001, almost one-half of electric toothbrushes sold in the United States have been Crest SpinBrushes.

Figure 2: Retail Power Toothbrush Sales in the United States

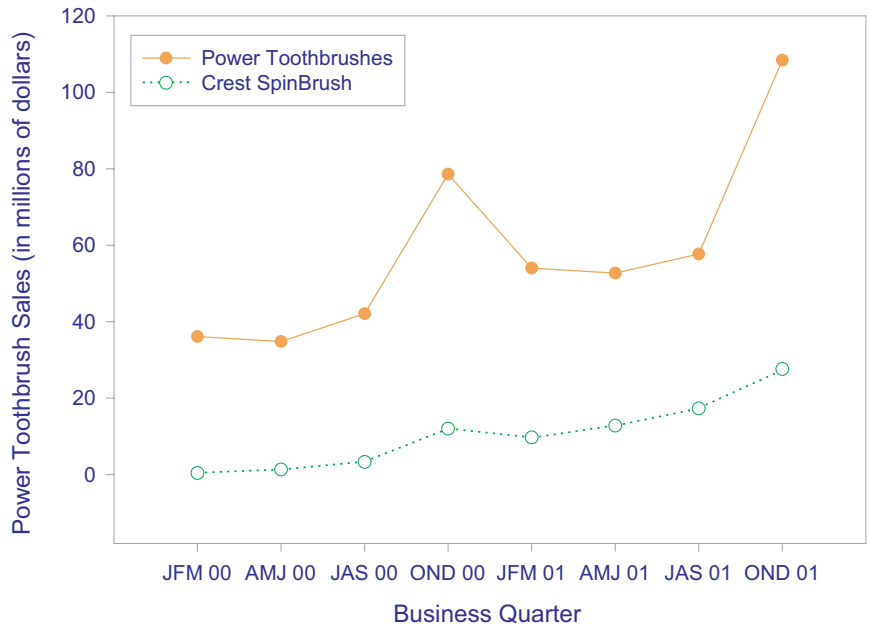

* Data represents combined food, drug, Kmart, \& Target stores, acquired from Information Resources, Incorporated (Chicago IL). 
Figure 3: Mean Power Toothbrush Retail Price

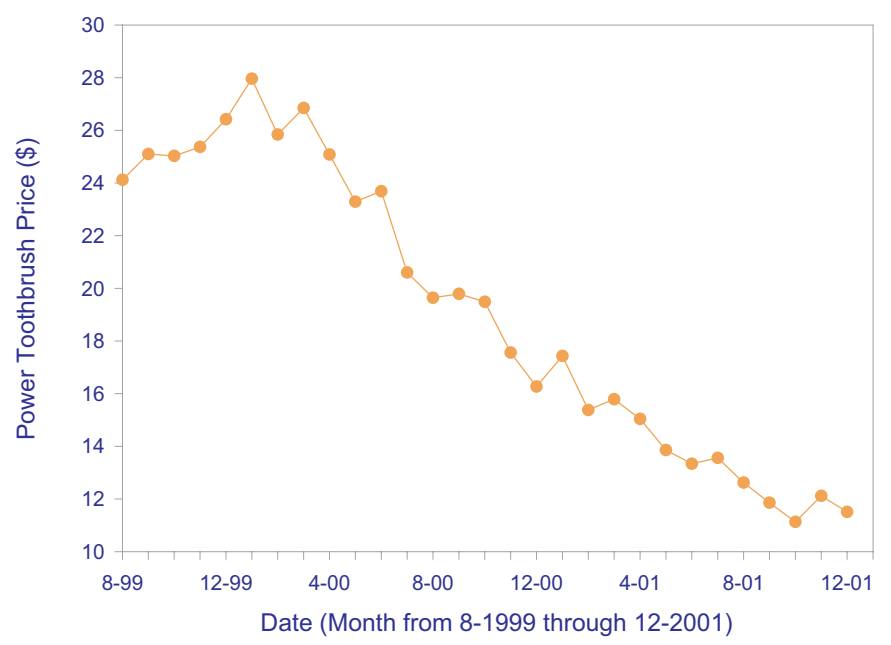

* Data represents combined food, drug, Kmart, \& Target stores, acquired from Information Resources, Incorporated (Chicago IL).

As a result of the popular interest generated by the new power toothbrush, the toothbrush market is fundamentally changing. Electric toothbrush technology is now accessible to the average toothbrush user. The average price of electric toothbrushes has been cut in half in the last two years. (Figure 3) The evolution of the power toothbrush market has led to a new wave of low priced battery operated toothbrushes that have been introduced by virtually all the major companies that market power and manual toothbrushes in the United States. (Figure 4) In addition, the expanding market for these lower price power toothbrushes has resulted in lower pricing of the more expensive power toothbrushes that were in the marketplace at the time Crest SpinBrush launched. The net result has been greater accessibility and value for toothbrush users seeking the oral benefits of oral hygiene with power toothbrushes.
Figure 4: Mean Retail Price of Competitive Power Toothbrush Brands

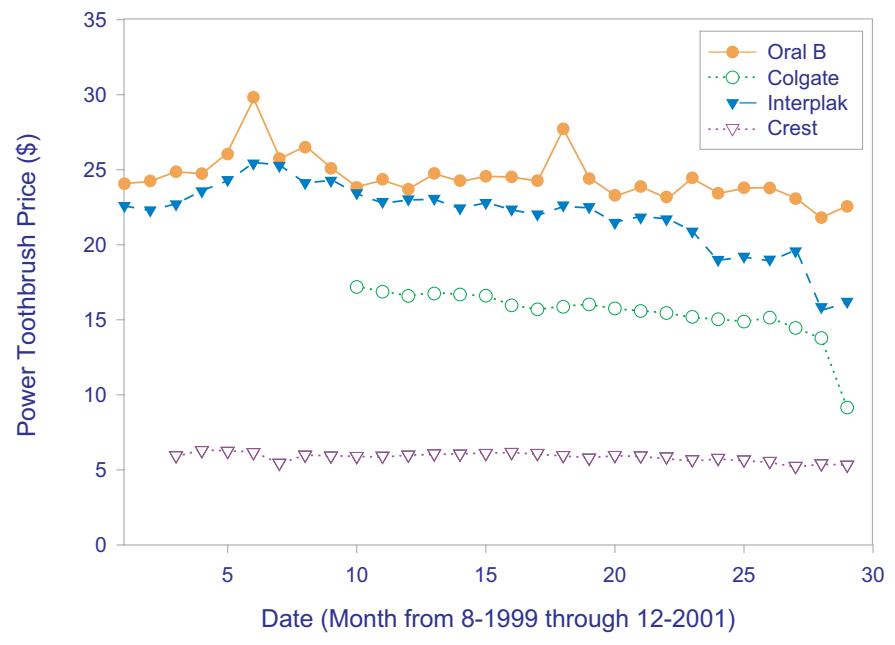

* Data represents combined food, drug, Kmart, \& Target stores, acquired from Information Resources, Incorporated (Chicago IL).

This price change in the broad market is largely due to the introduction and commercial success of this novel power toothbrush, which established a price point that did not exist two years ago. The recent growth in the power toothbrush market was largely driven by the under $\$ 10$ power toothbrush segment, where growth over the last two years has been explosive. (Table 6) These data also demonstrate that growth is coming from new power toothbrush consumers, as opposed to cannibalizing the high-end power toothbrush segment. While the overall unit sales of total toothbrushes have remained flat, the percentage of these units that are electric has tripled from $2.7 \%$ in 1999 to $9.5 \%$ in 2001 . This is driven by an important value equation, where consumers get the superior efficacy of power toothbrushes relative to manual toothbrushes at a price that is not dramatically higher than many manual toothbrushes.

Table 6: Sales of Powered Toothbrushes in the United States by Cost (1999 vs. 2001)

\begin{tabular}{|l|c|c|c|}
\hline \multirow{2}{*}{ Toothbrush Price } & \multicolumn{3}{|c|}{ Sales* in Dollars (in Thousands) } \\
\cline { 2 - 4 } & 1999 OND quarter & 2001 OND quarter & Index vs 1999 \\
\hline Brushes $<\$ 10$ & $\$ 641$ & $\$ 27,623$ & 4,309 \\
\hline Brushes $\$ 10-\$ 30$ & $\$ 33,611$ & $\$ 55,583$ & 165 \\
\hline Brushes $>\$ 30$ & $\$ 15,658$ & $\$ 25,170$ & 161 \\
\hline $\begin{array}{l}\text { ₹ Data represents combined food, drug, Kmart, \& Target stores, acquired from Infor mation Resources, Incorporated } \\
\text { (Chicago IL). }\end{array}$
\end{tabular}




\section{Benefits of the Novel Power Brush for Patients}

\section{Better plaque removal}

2 Increased brushing time for children and adults

3 Greater patient involvement in oral health

4 Financially feasible for more patients

\section{Summary}

Collectively, the data presented demonstrate that Crest SpinBrush is a highly effective cleaning toothbrush with respect to plaque removal. It has been shown to be superior to a number of manual toothbrushes that represent both ordinary and advanced design toothbrushes. In addition, it has been shown to be superior to a more expensive battery powered toothbrush. Finally, it has demonstrated comparable efficacy to a high priced leading powered toothbrush. In addition, separate research has confirmed adults and children tend to brush longer when using this new power toothbrush relative to manual toothbrushes. Increased brushing duration leads to increased plaque removal, suggesting that consumers likely receive a dual benefit with respect to cleaning: greater efficiency and longer brushing exposure. In parallel, this power toothbrush has also been shown to be safe relative to manual and power toothbrushes.

Importantly, the low cost of Crest SpinBrush has changed the power toothbrush marketplace. People are shifting to power toothbrushes in record numbers, primarily driven by the under $\$ 10$ power toothbrush sector. The growth is coming from new power toothbrush users, as opposed to the high-end power toothbrush segment. This is driven by an important value equation, where toothbrush users get the superior efficacy of power toothbrushes relative to manual toothbrushes at a price that is not dramatically higher than many manual toothbrushes. 


\section{References}

1. Warren PR, Chater B. The role of the electric toothbrush in the control of plaque and gingivitis: a review of 5 years clinical experience with the Braun Oral-B Plaque Remover [D7]. Am J Dent. 1996 Jul;9 Spec No:S5-11. Review.

2. van der Weijden GA, Danser MM, Nijboer A, et al. The plaque-removing efficacy of an oscillating/ rotating toothbrush. A short-term study. J Clin Periodontol. 1993 Apr;20(4):273-8.

3. van der Weijden FA, Timmerman MF, Piscaer M, et al. A comparison of the efficacy of a novel electric toothbrush and a manual toothbrush in the treatment of gingivitis. Am J Dent. 1998 Sep;11(Spec No):S23-8.

4. Cronin M, Dembling W, Warren PR, King DW. A 3-month clinical investigation comparing the safety and efficacy of a novel electric toothbrush (Braun Oral-B 3D Plaque Remover) with a manual toothbrush. Am J Dent. 1998 Sep;11(Spec No):S17-21.

5. van der Weijden GA, Timmerman MF, Nijboer A, et al. A comparative study of electric toothbrushes for the effectiveness of plaque removal in relation to toothbrushing duration. Timerstudy. J Clin Periodontol. 1993 Aug;20(7):476-81.

6. Yankell SL, Emling RC. A thirty-day evaluation of the Rowenta Dentiphant powered toothbrush in children for safety and efficacy. J Clin Dent. 1996;7(4):96-100.

7. Bustillo E, Cartwright S, Battista GW, et al. Effectiveness of a battery-powered toothbrush on plaque removal: comparison with four manual toothbrushes. Compend Contin Educ Dent Suppl. 2000;21(31):S25-9 quiz S35.

8. Nathoo S, Rustogi KN, Petrone ME, et al. Comparative efficacy of the Colgate Actibrush batterypowered toothbrush vs Oral-B CrossAction toothbrush on established plaque and gingivitis: a 6week clinical study. Compend Contin Educ Dent Suppl. 2000;21(31):S19-24; quiz S35.

9. Sowinski JA, Battista GW, Petrone DM, et al. Comparative efficacy of Colgate Actibrush batterypowered toothbrush and Colgate Plus (manual) toothbrush on established plaque and gingivitis: a 30-day clinical study in New Jersey. Compend Contin Educ Dent Suppl. 2000;21(31):S4-8; quiz S34.

10. Sharma N, Galustians HJ, Qaqish JG, et al. Comparative efficacy on supragingival plaque and gingivitis of a manual toothbrush (Colgate Plus) and a battery-powered toothbrush (Colgate Actibrush) over a 30-day period. Compend Contin Educ Dent Suppl. 2000;21(31):S9-13; quiz S34.

11. Soparkar PM, Rustogi KN, Petrone ME, Volpe AR. Comparison of gingivitis and plaque efficacy of a battery-powered toothbrush and an ADA-provided manual toothbrush. Compend Contin Educ Dent Suppl. 2000;21(31):S14-8; quiz S34.

12. Yankell SL, Emling RC. A thirty-day evaluation of the Rowenta Dentiphant powered toothbrush in children for safety and efficacy. J Clin Dent. 1996;7(4):96-100.

13. Borutta A. Plaque removal efficacy of a newly developed powered toothbrush in the primary dentition of pre-school children. J Clin Dent. 1997;8(6):151-5.

14. Jongenelis AP, Wiedemann W. A comparison of plaque removal effectiveness of an electric versus a manual toothbrush in children. ASDC J Dent Child. 1997 May-Jun;64(3):176-82, 165.

15. McCracken Gl, Stacey F, Heasman L, et al. A comparative study of two powered toothbrushes and one manual toothbrush in young adults. J Clin Dent. 2001;12(1):7-10.

16. Warren PR, Ray TS, Cugini M, Chater BV. A practice-based study of a power toothbrush: assessment of effectiveness and acceptance. J Am Dent Assoc. 2000 Mar;131(3):389-94.

17. Ruhlman CD, Bartizek RD, Biesbrock AR. Comparative efficacy of two battery-powered toothbrushes on dental plaque removal. J Clin Dent. 2002;13(3):95-9.

18. Ruhlman CD, Bartizek RD, Biesbrock AR. Plaque removal efficacy of a battery-operated toothbrush compared to a manual toothbrush. Am J Dent. 2001 Aug;14(4):191-4.

19. Heins PJ, Bartizek RD, Walter PA, Biesbrock AR. Plaque removal efficacy of a battery-operated power toothbrush compared to two control manual toothbrushes. Am J Dent 2002; In Press.

20. Hou L, Walters $P$, Bartizek $R$, Biesbrock $A$. Plaque removal by a battery-powered toothbrush relative to a manual toothbrush. J Dent Res 2002; 81(Special Issue A):A-399.

21. Biesbrock AR, Walters P, Bartizek RD, et al. Dental plaque removal with a novel battery-powered toothbrush relative to a positive control powered toothbrush. Am J Dent 2002; In Press 




\section{Linda M. Bayuk, MBA}



\section{Marie-Vee Santana, PhD}

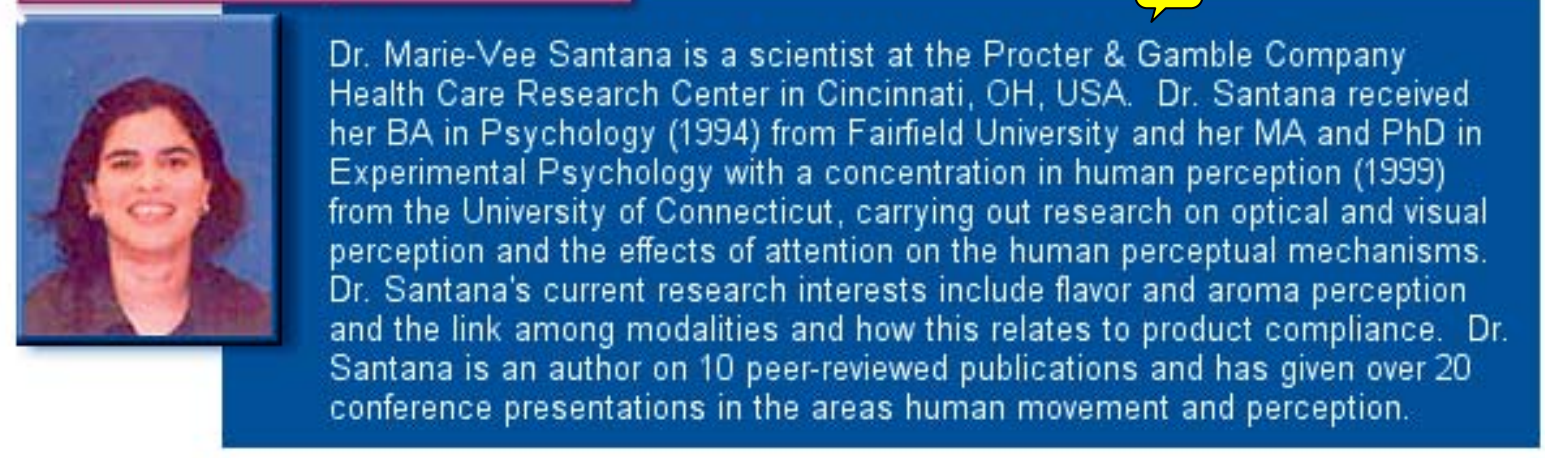

\section{Darin S, Yatos, MBA}

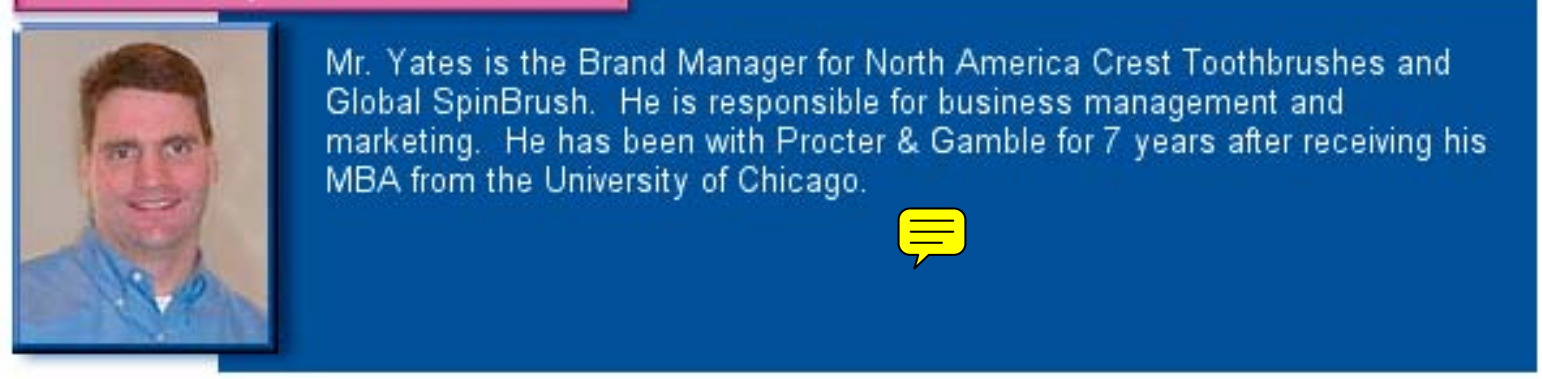




\section{Robert D. Bartizek, MS}

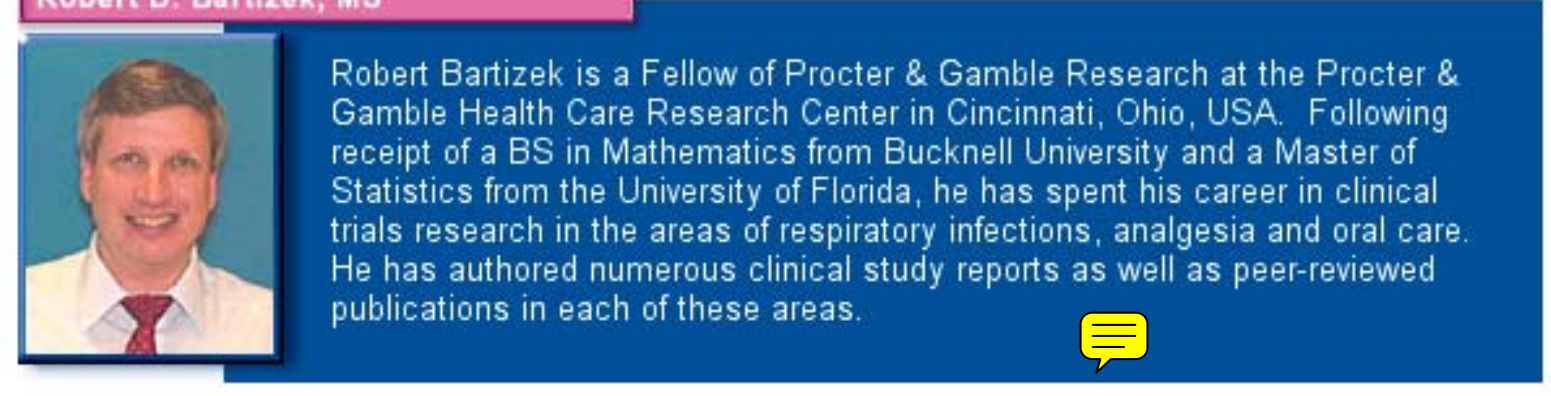

Acknowledgements

The authors would like to thank Lisa Prater for her work in preparing the manuscript and associated images. 